\title{
1 X 1000 kVA Transformer Measurement Analysis using Dyn-11 Vector Group and Off Load Tap Changer
}

\author{
Setiyo Budiyanto ${ }^{1}$, Lukman Medriavin Silalahi ${ }^{1,}$, Freddy Artadima Silaban ${ }^{1}$, Adi Kurnia ${ }^{1}$, \\ Agus Dendi Rochendi ${ }^{2}$, Muhammad Budi Haryono ${ }^{3}$, Mochamad Furqon Ismail ${ }^{4}$ \\ ${ }^{1}$ Department of Electrical Engineering, Faculty of Engineering, Universitas Mercu Buana, Indonesia \\ ${ }^{2}$ Department of Oceanographic physics, Lembaga Ilmu Pengetahuan Indonesia, Indonesia \\ ${ }^{3}$ Department of Materials Science and Engineering, Faculty of Engineering, Beijing Institute of Technology, China \\ ${ }^{4}$ Department of Physical Oceanography, Geomar Helmholtz Centre for Ocean Research Kiel, Germany
}

\begin{abstract}
The transmission line of electrical energy generated by the power plant is usually located far from the load center to be distributed to the community. The substation is part of a distribution transmission line that acts as a control center and consists of a collection of extra high voltage equipment. Routine maintenance of the power transformer as the main equipment of the substation must be scheduled so that its performance remains reliable. The proposed method of this research is to analyze the condition of the transformer through testing when it is off, to the calculation of the transformer ratio to determine the condition of the transformer windings using the calculation of the formula and measurement of the Raytech Transformer Turn Ration measuring instrument. In this research, the Raytech Transformer Turn Ratio measurement tool is used to determine the ratio of the winding input voltage of 20,000 volts and the output voltage of 400 volts on the power transformer. At a voltage of 40VAC, from the results of the comparisons that have been made, it can be seen that the test results of the Raytech Transformer Turn Ratio measuring instrument, if it crosses the $0.5 \%$ tolerance limit, the measurement results on one of the coils change the ratio. If the transformer is not regularly checked, the impact will result in unbalance of voltage on one of the coils. And one of the coils in phase will expand and cause a loss of voltage.
\end{abstract}

\author{
Keywords: \\ Off Load Tap Changer \\ Transformer; \\ Transmission Line; \\ Transformer Turn Ratio, \\ Article History: \\ Received: April 4, 2021 \\ Revised: November 4, 2021 \\ Accepted: November 8, 2021 \\ Published: November 25, 2021 \\ Corresponding Author: \\ Lukman Medriavin Silalahi, \\ Electrical Engineering Department, \\ Universitas Mercu Buana, \\ Indonesia \\ Email: lukman.medriavin \\ @mercubuana.ac.id
}

\section{INTRODUCTION}

Public life and electrical energy are two things that cannot be separated in this modern era [1]. The availability of adequate electricity is a prerequisite for improving people's welfare through the industrial sector [2], the development sector [3], and the economic sector [4], which must be accompanied by an electric power system with a high level of quality and reliability. The electric power system consists of a generating system, transmission, and distribution system [5]. The power plant location that is not always close to the load center means that electricity must be channeled through transmission and distribution lines to reach consumers. One part that cannot be separated from the distribution transmission line is the substation. The substation is a collection of extra-high voltage electrical equipment that has an important role in transforming electrical power as well as a control center to coordinate between the generating system and the distribution system $[6,7,8,9]$.

A transformer is an electrical device that can change the level of an AC voltage to another level. The purpose of changing these levels includes reducing the voltage or increasing the 
voltage. This transformer or transformer works based on the principle of electromagnetic induction and can only work on alternating current (AC) $[10,11,12]$. Transformers (transformers) play a significant role in the distribution of electricity. The transformer raises the electricity from the PLN power plant to hundreds of kilovolts for distribution. Then the other transformers reduce the voltage required by every household and office, which generally uses 220Volt AC voltage. Therefore, a transformer is the most important asset in the electricity transmission and distribution system. Apart from correct routine maintenance, testing is also necessary to detect any disturbances or damage to the transformer. So doing various measurements that describe the actual condition of the equipment being measured is one way to prevent damage to the transformer. The transformer tests are carried out according to SPLN'50-1982 [13] by going through three kinds of tests described in IEC 76 (1976): routine tests, type tests, and special tests. One of the transformer measurements is using a TTR (Transformer Turn Ratio) measuring instrument. This is important for the correct prediction of the transformer condition. Therefore, this research was conducted to predict and assess the performance of the transformer so as to minimize and prevent transformer failures that can harm many aspects. The operational feasibility of a power transformer can be determined after going through the stages of testing based on applicable standards. The reliability of the transformer during the operation period is largely determined by the way it is maintained, so that maintenance is needed for the reliability of the transformer $[14,15,16]$.

The purpose of this research is to determine the ratio on the primary and secondary sides of a $1000 \mathrm{kVA}$ power transformer with a primary voltage of 20,000 Volt and a secondary 400 Volt using an Off-Load Tap Changer. Then, observe and operate the use of the Raytech Transformer Turn Ratio comparison tool on the primary and secondary side of the transformer directly. Thus, a measuring instrument is $1000 \mathrm{kVA}$, resulting in comparisons between manual calculations using the Raytech Transformer Turn Ratio. The research output obtained is that the transformer secondary voltage error is known so that the condition of the transformer itself can be analysed, which refers to the tolerance limits issued by IEEE C57.125.1991.

\section{METHOD}

A transformer is a device that transfers electrical energy from one circuit to another, or multiple circuits. A changing current in any one transformer coil causes a changing magnetic flux in the core, which causes a changing electromotive force across all other coils wound around the same core. Without a metallic (conductive) connection between the two circuits, electrical energy can be transferred between them. The induced voltage effect in any coil due to a changing magnetic flux encircling the coil is described by Faraday's law of induction, which was discovered in $1831[17,18]$.

In electric power applications, transformers are commonly used to increase low $\mathrm{AC}$ voltages at high current (a step-up transformer) or decrease high AC voltages at low current (a step-down transformer), as well as to connect the stages of signal-processing circuits. With separate coils that are not electrically bonded to one another, transformers can also be used for isolation, where the voltage in equals the voltage out. Transformers have become indispensable for the transmission, distribution, and use of alternating current electric power since the invention of the first constant-potential transformer in 1885. In electronic and electric power applications, a variety of transformer designs are used. Transformers range in size from RF transformers with a volume of less than a cubic centimeter to power grid interconnectors weighing hundreds of tons. Figure 1 shows some examples of $1 \mathrm{X} 1000 \mathrm{kVA}$ Transformer [19, 20]. 

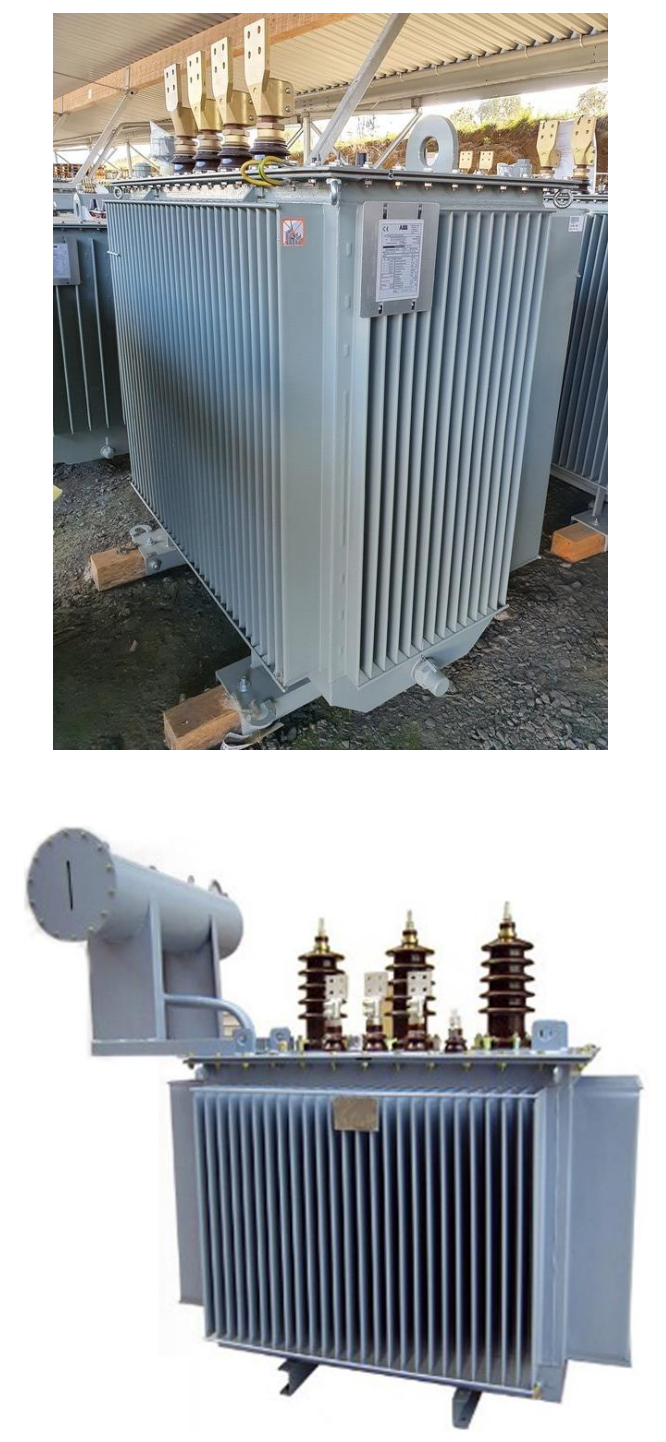

Figure 1. Examples of 1 X $1000 \mathrm{kVA}$ Transformer

Figure 2 shows a schematic flowchart of the proposed research methodology. This test is carried out on the transformer in an off state (not on voltage) because it uses an offload tap changer by changing the tapping on the transformer and connecting the Raytech Transformer Turn Ratio gauge to the ratio value data is obtained on the transformer. The output of the measuring instrument is then compared with a manual calculation to produce an analysis result of the measurement of a 1 x $1000 \mathrm{kVA}$ transformer using the Dyn-11 vector group and offload tap changer.

Based on Figure 3, to compare the primary and secondary windings in the transformer, the first thing to prepare is the Raytech Transformer Turn Ratio measuring instrument. The Raytech Transformer Turn Ratio meter has four output connector cables. One red cable and one black cable for the primary side, one red cable, and one black cable for the secondary side. It should be noted in installing the connector cable so that it is not arbitrary and must be adjusted to the Dyn-11 vector group on the transformer being tested, as shown in Figure 3. 


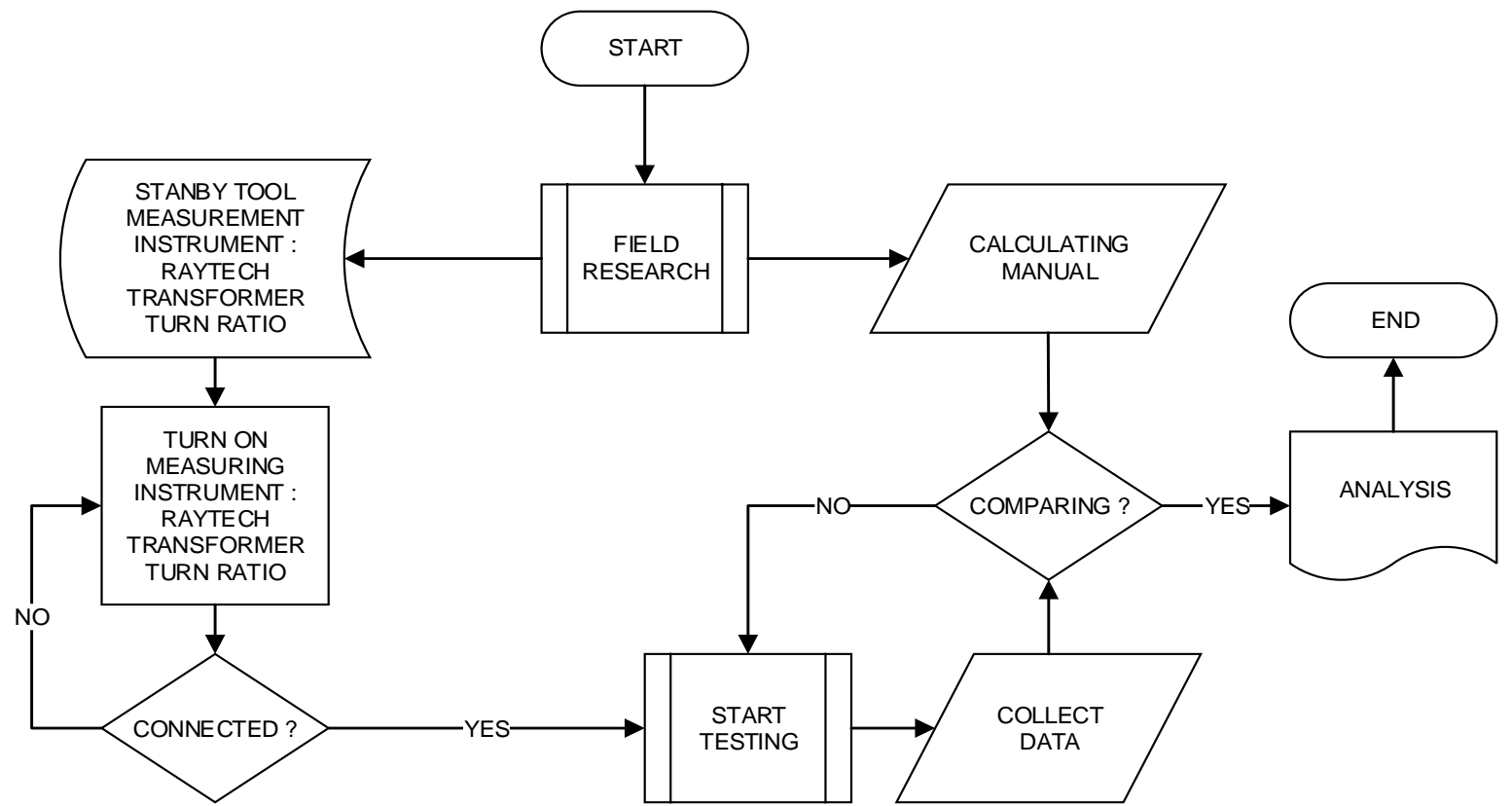

Figure 2. Flowchart Research Design

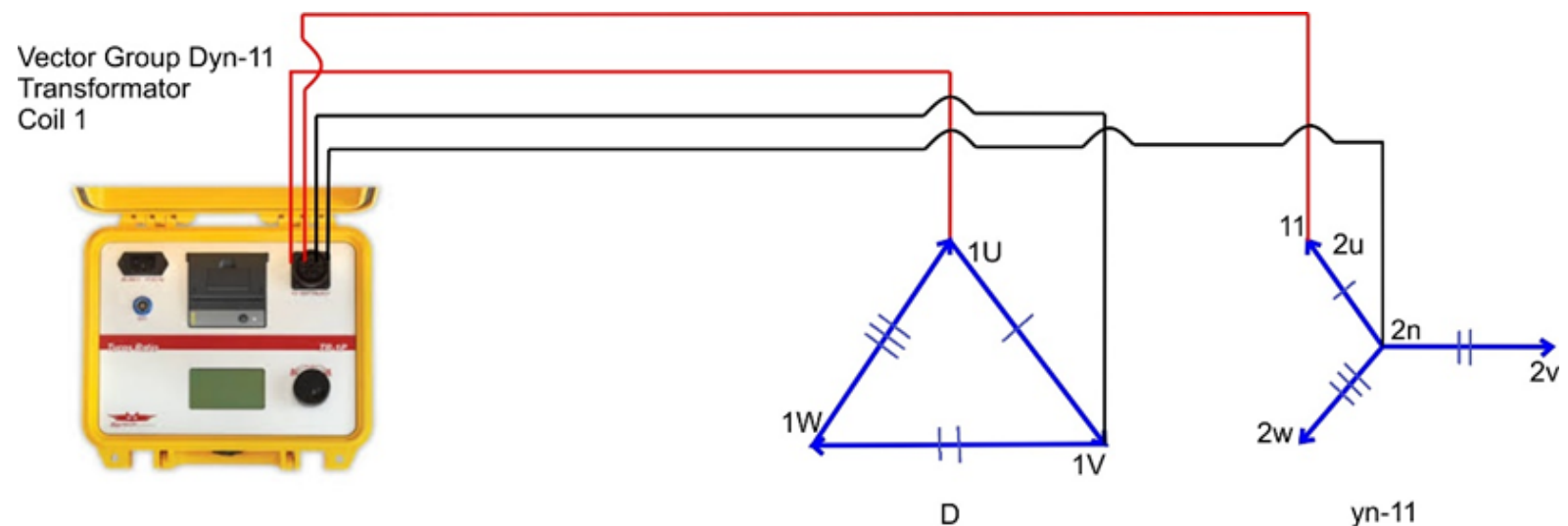

Figure 3. Installation of the Raytech Transformer Turn Ratio Connector to the Vector Group Dyn-11 on Coil 1 (Phase U)

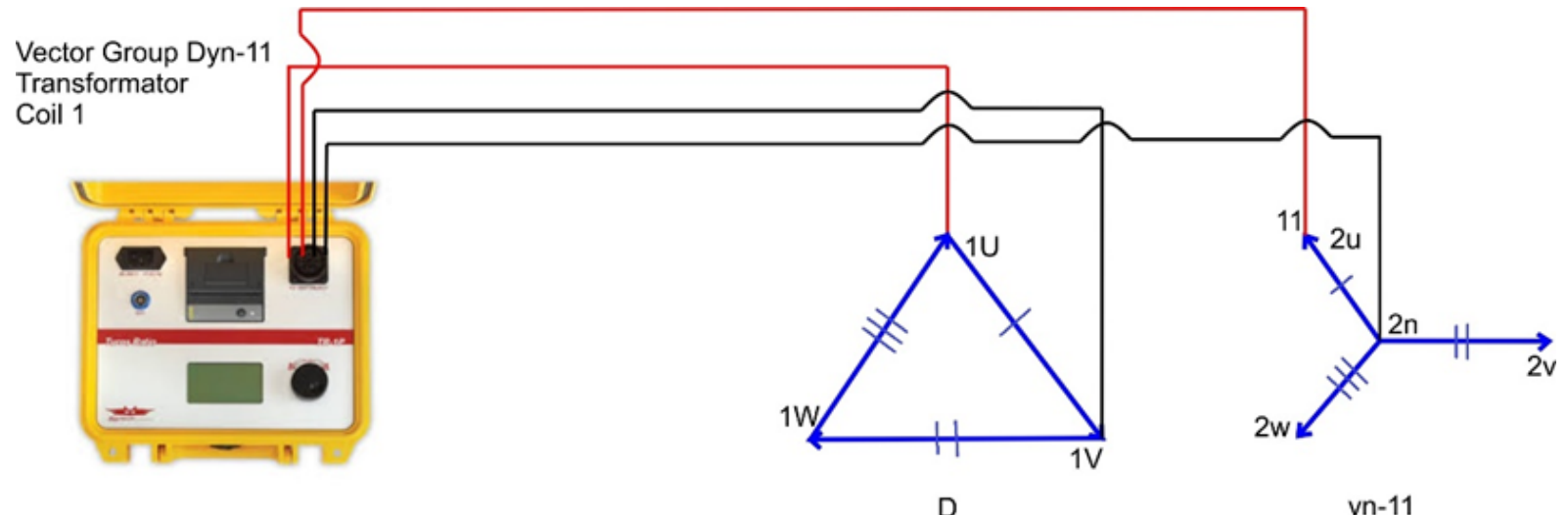

Figure 4. Installation of the Raytech Transformer Turn Ratio Connector to the Vector Group Dyn-11 on Coil 2 (Phase V) 


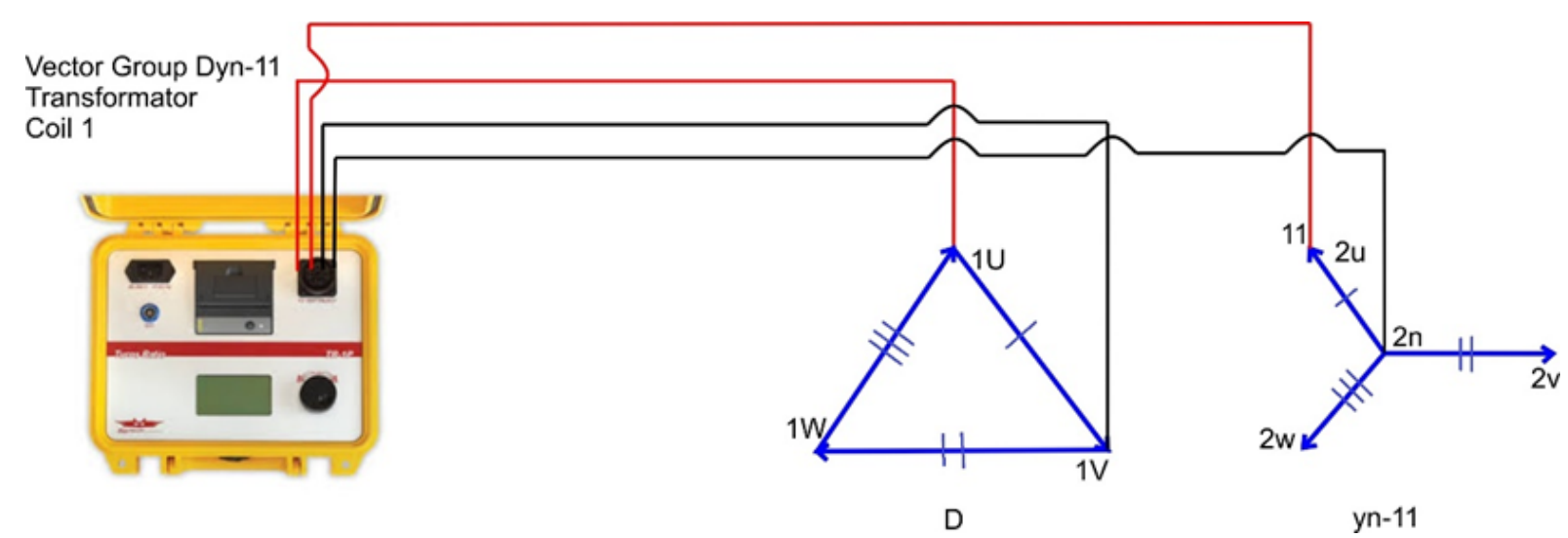

Figure 5. Installation of the Raytech Transformer Turn Ratio Connector to the Vector Group Dyn-11 on Coil 3 (Phase W)

Figure 3 shows the connection of coil 1 to the Raytech Transformer Turn Ratio gauge. On the primary side one red wire is connected to the root bushing (phase $1 \mathrm{U}$ ), one black wire is connected to the root bushing (phase $1 \mathrm{~V}$ ). On the secondary side one red wire is connected to the root bushing $(2 \mathrm{u})$, one black wire is connected to the root bushing $(2 \mathrm{n})$. Figure 4 shows the connection of coil 2 to the Raytech Transformer Turn Ratio gauge. Again, on the primary side, one red wire is connected to the root bushing (phase 1V), one black wire is connected to the root bushing (phase $1 \mathrm{~W}$ ). On the secondary side one red wire is connected to the root bushing (2v), one black wire is connected to the root bushing (2n).

Figure 5 shows the connection of coil 3 to the Raytech Transformer Turn Ratio gauge. On the primary side one red wire is connected to the root bushing (phase $1 \mathrm{~W}$ ), one black wire is connected to the root bushing (phase $1 \mathrm{U}$ ). On the secondary side, one red wire is connected to the root bushing $(2 \mathrm{w})$, one black wire is connected to the root bushing $(2 \mathrm{n})$.

From the test results using the Raytech Transformer Turn Ratio measuring instrument, the resulting data output is then compared with the following formula:

$$
\frac{\text { HVTap }}{L V / \sqrt{3}}
$$

The Raytech Transformer Turn Ratio measurement results are tolerated $\pm 0.5 \%$ of the dividing result using the formula. This tolerance reference is based on the IEEE C57.125.1991 standard. This tolerance has functioned so that the Raytech Transformer Turn Ratio measurement results have a maximum and minimum allowable ratio. For example, the following calculation characterizes tolerance of $0.5 \%$ :

$$
\begin{array}{r}
0.5 \%=0.005 \\
1+0005=1.005(\mathrm{Max}) \\
1-0.005=0.995(\mathrm{Min})
\end{array}
$$

\section{RESULTS AND DISCUSSION}

Figure 6 shows the results of measurements using the Raytech Transformer Turn Ratio measuring instrument, which will then be recorded and analyzed after comparisons are obtained by performing manual calculations as shown in (3), (4), (5), (6) and (7).

$$
\text { Tapping } 1=\frac{H V T a p}{L V / \sqrt{3}}=\frac{21000}{400 / \sqrt{3}}=90,93
$$




$$
\begin{aligned}
& \text { Tapping } 1=\frac{H V T a p}{L V / \sqrt{3}}=\frac{20500}{400 / \sqrt{3}}=88,76 \\
& \text { Tapping } 1=\frac{H V T a p}{L V / \sqrt{3}}=\frac{20000}{400 / \sqrt{3}}=86,60 \\
& \text { Tapping } 1=\frac{H V T a p}{L V / \sqrt{3}}=\frac{19500}{400 / \sqrt{3}}=88,43 \\
& \text { Tapping } 1=\frac{H V T a p}{L V / \sqrt{3}}=\frac{19000}{400 / \sqrt{3}}=88,27
\end{aligned}
$$

Tolerance_Tapping1_max $=(3) \times$ tolerance $\_\max =90.93 \times 1.005=91.38$

Tolerance_Tapping1_min $=(3) \times$ tolerance $\_\min =90.93 \times 0.995=90.48$

Tolerance_Tapping2_max $=\left(4 \times\right.$ tolerance $\_\max =88.76 \times 1.005=89.20$

Tolerance_Tapping2_ $\min =(4) \times$ tolerance $\_\min =88.76 \times 0.995=88.32$

Tolerance_Tapping3_max $=(5) \times$ tolerance_max $=86.60 \times 1.005=87.03$

Tolerance_Tapping3_ $\min =(5) \times$ tolerance $\_\min =86.60 \times 0.995=86.17$

Tolerance_Tapping4_max $=(6) \times$ tolerance_max $=88.43 \times 1.005=84.85$

Tolerance_Tapping4_min $=(6) \times$ tolerance $\_\min =88.43 \times 0.995=84.01$

Tolerance_Tapping5_max $=(7) \times$ tolerance_max $=88.27 \times 1.005=82.68$

Tolerance_Tapping5_min $=(7) \times$ tolerance_ $\min =88.27 \times 0.995=81.86$

Based on the results of the data that has been collected between the effects of manual calculations and measurements using the Raytech Transformer Turn Ratio measuring instrument, it can be seen that the tolerance is shown in (8) to (17). So that from the several steps that have been taken, starting from measurements using the Raytech Transformer Turn Ratio measuring instrument, followed by manual mathematical calculations until a tolerance value is obtained, finally it can be analyzed in this research as follows:

1. In winding measurement, the transformer ratio must be between the minimum and maximum values set at $0.5 \%$ of the voltage ratio, which refers to the IEEE C57.125.1991 standard. If the above measurement results do not match, the transformer must be repaired by increasing or decreasing the winding on the primary side. If repairs are not done, one of the phases from the secondary side of the transformer can be lost. So that, the transformer coil is damaged and even damages the load, e.g., equipment connected to transformers. Some damages, such as electric motors and so on, are due to unbalanced voltages or those required by the load.

2. An error reading on the measuring instrument can cause a mismatch in the number of transformers turns. In the measurement results using the stipulated conditions, comparisons can be made with calculation analysis and also periodic calibration of measuring instruments. 


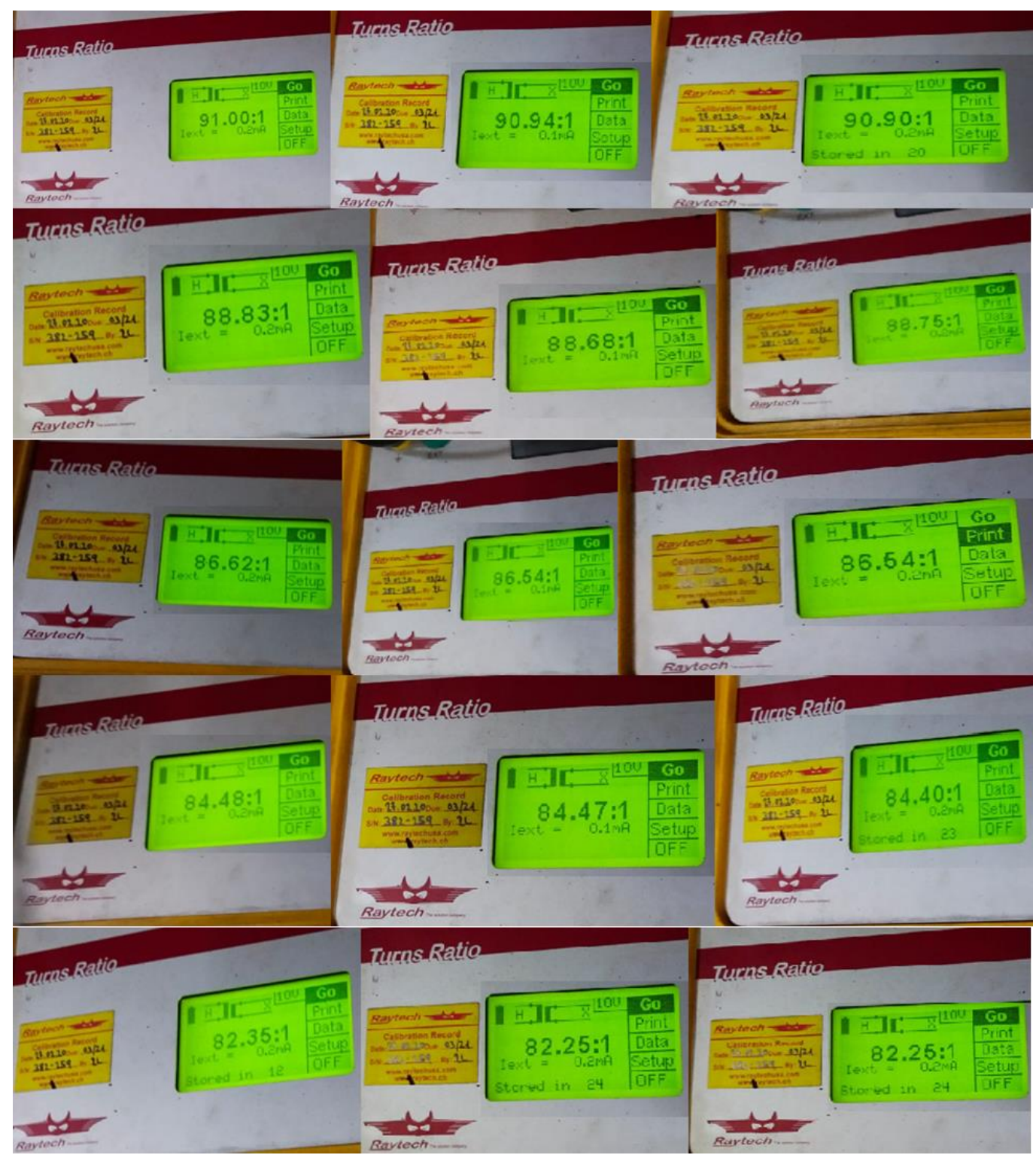

Figure 6. Raytech Transformer Turn Ratio Measurement Coil 1 (Left side - 5 times); Raytech Transformer Turn Ratio Measurement Coil 2 (Center side - 5 times); Raytech Transformer Turn Ratio Measurement Coil 3 (Right side five times)

\section{CONCLUSION}

Several tests and results using the Raytech Transformer Turn Ratio measuring instrument and comparisons using the formula have been performed. Some conclusions are obtained about the research carried out, including comparing based on the comparisons of coils that have been done. If the test results use the Raytech Transformer Turn Ratio measuring instrument, if it crosses the $\pm 0.5 \%$ limit, it can be seen that the measurement results of one of the coils have changed the ratio. The results of testing with the Raytech Transformer Turn Ratio measuring instrument that has been carried out are then compared with the manual formula calculation. If the Raytech Transformer Turn Ratio is not routinely checked on the transformer, it will unbalance of voltage on one of the coils. And one of the coils in phase will expand and cause a loss of voltage (error) or cause damage to the load (other equipment) due to the unbalanced voltage. If the protective device used is in good condition, the protection device will strip the CB. 


\section{REFERENCES}

[1] H. Ichikawa, S. Yokogawa, Y. Kawakita, K. Sawada, T. Sogabe, A, Minegishi, \& H. Uehara, “An approach to renewable-energy dominant grids via distributed electrical energy platform for IoT systems," In 2019 IEEE International Conference on Communications, Control, and Computing Technologies for Smart Grids (SmartGridComm), Beijing, China, 2019, pp. 1-6, doi: 10.1109/SmartGridComm.2019.8909762.

[2] T. M. Gür, "Review of electrical energy storage technologies, materials and systems: challenges and prospects for large-scale grid storage," Energy \& Environmental Science, vol. 11, no. 10, pp. 2696-2767, 2018, doi: 10.1039/C8EE01419A

[3] A. Lanko, F. J. S. de la Flor, \& Y. Geraskin, "The Analysis of Multi-Apartment Residential Buildings Energy Consumption in Russia," In E3S Web of Conferences, EDP Sciences, 2020, vol. 217, pp. 01003, doi: 10.1051/e3sconf/202021701003.

[4] P. Nikolaidis \& A. Poullikkas, "A comparative review of electrical energy storage systems for better sustainability," Journal of Power Technologies, vol. 97, no. 3, pp. 220-245, 2017

[5] M. Rezkalla, M. Pertl, \& M. Marinelli, "Electric power system inertia: requirements, challenges and solutions," Electrical Engineering, vol. 100, no. 4, pp. 2677-2693, 2018, doi: 10.1007/s00202-018-0739-z

[6] H. Fathabadi, "Novel fuel cell/battery/supercapacitor hybrid power source for fuel cell hybrid electric vehicles," Energy, vol. 143, pp. 467-477, 2018, doi: 10.1016/j.energy.2017.10.107

[7] Z. Shiling, "Research of electric field strength on surface of conductor and its splitting type used in extra high voltage substation," Journal of Physical of Conference Series, vol. 1858, 012062, 2021

[8] Darjat, J. Windarto, and J. Prasetyo, "Simulation Design of Ungaran 500kv Substation Operation System Using Microcontroller,” Journal of Physical of Conference Series, vol. 1904, 012027, 2021

[9] V. Kuchanskyy, I. Zaitsev, M. Bajaj, O. Rubanenko and I. Hunko, "Method for Calculation Controlled Compensating Devices Parameters Extra High Voltage Power Lines," 2021 IEEE 3rd Ukraine Conference on Electrical and Computer Engineering (UKRCON), 2021, pp. 385-390, doi: 10.1109/UKRCON53503.2021.9575432.

[10] G. Xu, Z. Zhu, A. Wang, W. Zhang, F. Sun and F. Zhao, "Automatic verification device and method for transformer turns ratio tester," 2017 Chinese Automation Congress (CAC), Jinan, China, 2017, pp. 29302933, doi: 10.1109/CAC.2017.8243276.

[11] Y. Duan and K. Li, "Computer Simulation Analysis of Power Transformer Test Design Technology," Journal of Physical of Conference Series, vol. 1648, 032188, 2020

[12] V. A. Thiviyanathan, P. J. Ker, Y. S. Leong, M. Z. B. Jamaluddin and L. H. Mun, "Detection of 2FAL Furanic Compound in Transformer Oil Using Optical Spectroscopy Method and Verification Using Morse Oscillation Theory," in IEEE Access, vol. 8, pp. 76773-76779, 2020, doi: 10.1109/ACCESS.2020.2989432.

[13] NN, "Spesifikasi Transformator Distribusi. Nomor: D3.002-1," Standart Perusahaan Listrik Negara, Jakarta: Perusahaan Listrik Negara (PLN), 2007.

[14] M. T. A. Khan, A. A. Milani, A. Chakrabortty, \& I. Husain, "Dynamic modeling and feasibility analysis of a solid-state transformer-based power distribution system," IEEE Transactions on Industry Applications, vol. 54, no. 1, pp. 551-562, 2017, doi: 10.1109/TIA.2017.2757450.

[15] T. W. Hariyadi \& A. Adriansyah, "Comparison of DC-DC Converters Boost Type in Optimizing the Use of Solar Panels," In 2020 2nd International Conference on Broadband Communications, Wireless Sensors and Powering (BCWSP), Yogyakarta, Indonesia, 2020, pp. 189-194, doi: 10.1109/BCWSP50066.2020.9249464.

[16] I. Misra, R. Girdhar, and A. Joulin, "An End-to-End Transformer Model for 3D Object Detection," Proceedings of the IEEE/CVF International Conference on Computer Vision (ICCV), 2021, pp. 2906-2917

[17] M. Rafiq, M. Shafique, A. Azam, M. Ateeq, "Transformer oil-based nanofluid: The application of nanomaterials on thermal, electrical and physicochemical properties of liquid insulation-A review," Ain Shams Engineering Journal, vol. 12, no. 1, pp. 555-576, doi: 10.1016/j.asej.2020.08.010

[18] Z. Shen, F. Wang, Z. Wang, J. Li, "A critical review of plant-based insulating fluids for transformer: 30year development," Renewable and Sustainable Energy Reviews, vol. 141, 110783, 2021, doi: 10.1016/j.rser.2021.110783

[19] F. A. Acheampong, H. Nunoo-Mensah, and W. Chen, "Transformer models for text-based emotion detection: a review of BERT-based approaches," Artificial Intelligence Review, vol. 54, pp. 5789-5829, 2021, doi: 10.1007/s10462-021-09958-2

[20] A. A. M. Faudzi and N Zhang, "Analysis on the Performance of a Second-order and a Third-order RLC Circuit of PRBS Generator," Journal of Integrated and Advanced Engineering (JIAE), vol. 1, no. 1, pp. 110, 2021, doi: 10.51662/jiae.v1i1.7 